\title{
Immunocytochemical localization of carbonic anhydrase, NaK-ATPase and the bicarbonate chloride exchanger in the anterior segment of the human eye
}

\author{
H. Holthöfer, G. J. Siegel, A. Tarkkanen and T. Tervo \\ Department of Bacteriology and Immunology and Department of Ophthalmology, \\ University of Helsinki, Helsinki, Finland, and \\ Department of Neurology, University of Michigan Medical Center, Ann Arbor, Michigan, USA
}

\begin{abstract}
We examined immunohistochemically the localization of three transport enzymes (carbonic anhydrase, Ca-II; sodium-potassium-activated adenosine triphosphatase, NaK-ATPase; bicarbonate-chloride exchanger, band III) in the anterior segment of the human eye. In accord with earlier studies, NaK-ATPase was primarily found in the corneal endothelium, but also in the corneal basal epithelial cell membranes. In addition, immunoreactivity for NaK-ATPase was observed in the nonpigmented epithelium of the ciliary processes and between the two epithelial cell layers. Ca-II immunoreactivity was found in the corneal endothelium as well as in the non-pigmented epithelial layer of the ciliary processes. Interestingly, band III immunoreactivity was found in the corneal endothelium, as similar to Ca-II, but not in the ciliary processes. These results show that, similar to many other tissues, Ca-II and band III immunoreactivities colocalize in the same cytologic site in the human corneal endothelium. Immunocytochemical detection of these key transport enzymes not only gives their accurate and reliable anatomical distribution, but also provides information on the electrolyte transport at these sites.
\end{abstract}

Key words: immunohistochemistry - carbonic anhydrase bicarbonate-chloride exchanger - NaK-ATPase.

Formation of the aqueous humor (AH) takes place by an active, energy dependent mechanism in the epithelial cells of the ciliary process. AH is transported into the anterior chamber through the pupillary aperture, leaves the globe via the trabecular meshwork and enters the aqueous veins (Cole
1977). In the cornea, the endothelium is mainly responsible for the regulation of dehydrating and retaining of the transparency of the corneal stroma by compensating the leakage of $\mathrm{AH}$ into the stroma by active pumping of water and electrolytes back into the anterior chamber (Bonting \& Becker 1964; Maurice 1957, 1972; Riley 1982). Various enzyme activities in the ciliary epithelium (Cole 1964; Shiose \& Sears 1966) and corneal endothelium are known to be crucially involved in both the production of AH (Bonting et al. 1961; Riley \& Peters 1981) and in the regulation of the intraocular pressure or maintenance of corneal transparency (Maurice 1957; Riley 1982). Particularly, carbonic anhydrase, catalyzing the hydration of carbon dioxide to ultimately yield bicarbonate and protons, is important in transport physiology as evidenced by the clinical efficiency of acetazolamide to decrease aqueous humour formation (Becker 1959; Becker \& Constant 1955). A second enzyme, sodium-potassium activated adenosine triphosphatase (NaK-ATPase), regulates the exchange of intracellular sodium to extracellular potassium, and is present both in the structures producing $\mathrm{AH}$ (Flügel \&c Lütjen-Drecoll 1988) and in the cornea (Bonting et al. 1961).

The exact cellular sites for the enzyme activities involved in the regulation of AH production in the human eye have remained somewhat controversial due to the limited specificity of histochemical pro- 
cedures (Guth \& Albers 1974; Leuenberger \& Novikoff 1974; Tervo et al. 1977). However, the recently introduced immunocytochemial methods (Kashgarian 1984; Holthöfer 1987; Holthöfer et al. 1987) have been shown to be useful for the precise localization of specific transport enzyme antigenicities.

In this study we examined the immunohistochemical localization of carbonic anhydrase, NaKATPase and a bicarbonate-chloride exchanger, band III glycoprotein, in the anterior segment of the human eye.

\section{Materials and Methods}

Anterior segments from three human eyes were obtained from enucleations due to large uveal malignant melanomas (Department of Ophthalmology, University of Helsinki). The tumour did not extend anterior to the ora serrata in any of the cases and the corneal sensitivity wea checked to be normal. None of the patients showed any noticeable cataract formation. The posterior half of the eyes was paraffin embedded and used for histological examination of the tumor and verification of the diagnosis. The tissue samples to be studied were fixed in $70 \%$ ethanol at room temperature in 0.1 M phosphate buffer (PBS, pH 7.4). The samples were subsequently sectioned with a microtome at $15 \mu \mathrm{m}$ and, after thorough washing in PBS treated according to the indirect immunofluorescence technique (see below).

The antibodies used were: Anticarbonic anhydrase (isoenzyme II; Ca-II), which was grown and characterized as extensively documented earlier (Kumpulainen 1979, 1983). This antibody was generously provided by Dr. T. Kumpulainen (Department of Anatomy, University of Oulu, Finland). The rabbit antisodium-potassium activated adenosine triphosphatase (NaK-ATPase; Ernst 1972; Siegel et al. 1984) and antibicarbonate chloride exchanger (band III glycoprotein) have been extensively characterized earlier (HazenMartin et al. 1986; Holthöfer et al. 1987, 1990). The antiband III antibodies were kindly provided by Dr. D. Biemesderfer (Department of Cell Biology, Yale University, New Haven, USA) whereas the antiNaK-ATPase was from one of the authors (GJS).

Fluorescein isothiocyanate (FITC) labelled anti- rabbit IgG (Dakopatts a/s, Glostrup, Denmark) was used as second antibodies.

The staining sequence included incubation of the tissue sections with appropriate dilutions of the primary antisera (1:100 for antiCa-II and antiband III, and $50 \mu \mathrm{m} / \mathrm{ml}$ for antiNaK-ATPase in PBS) for $30 \mathrm{~min}$ at room temperature, followed by thorough rinsing and incubation with the second antibodies. A Leitz Diaplan fluorescence microscope equipped with a filter system for FITC fluorescence was used. Control experiments included incubation of the sections with non-immune rabbit serum, or omission of either the primary or secondary antibody from the staining sequence. These resulted in no specific fluorescence.

\section{Results}

\section{NaK-ATPase}

NaK-ATPase-specific immunoreactivity was observed in the membranes of the basal cells of the corneal epithelium (Fig. 1). In addition to this, strong reactivity was found in the corneal endothelium (Fig. 2a). In the ciliary processes, mainly the non-pigmented epithelium showed reactivity for NaK-ATPase. The adjoining membranes of the two ciliary epithelia appeared reactive, too (Fig. 3a).

\section{Ca-II}

Immunoreactivity for Ca-II was prominently seen in the capillary endothelia of the limbus. However, reactivity was also observed in the corneal endothelium (Fig. 2b). In the ciliary process, the nonpigmented epithelial layer showed moderate immunoreactivity (Fig. 3b).

\section{Band III}

Immunostaining for band III failed to show any reactivity in the corneal epithelium, but was found in the corneal endothelium (Fig. 2c). On the other hand, no specific fluorescence was found in the ciliary processes (Fig. 3c).

\section{Discussion}

The results of this study reveal the exact localization of the key transport enzymes involved in the regulation of both $\mathrm{AH}$ production and corneal transparency in the human eye. All the antibodies used have been extensively characterized for tissue 

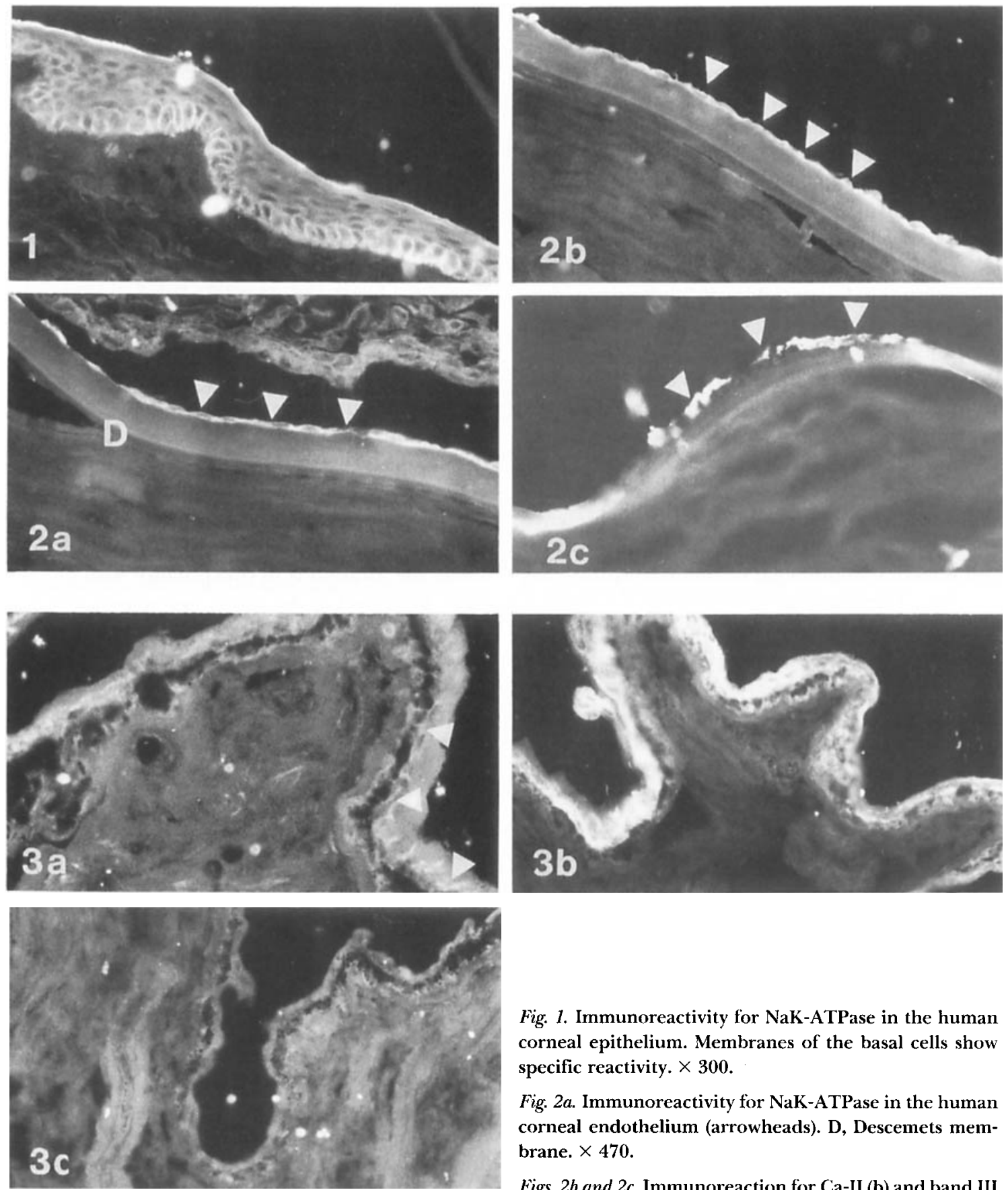

Fig. 1. Immunoreactivity for NaK-ATPase in the human corneal epithelium. Membranes of the basal cells show specific reactivity. $\times 300$.

Fig. 2a. Immunoreactivity for NaK-ATPase in the human corneal endothelium (arrowheads). D, Descemets membrane. $\times 470$.

Figs. $2 b$ and $2 c$. Immunoreaction for Ca-II (b) and band III (c) in the human corneal endothelium. $\times 470$.

Figs. $3 a, 3 b$ and $3 c$. Immunoreaction for NaK-ATPase (a), $\mathrm{Ca}-\mathrm{II}$ (b) and band III (c) in the epithelial layers of the human ciliary process. The inner non-pigmented epithelium is more intensely decorated for both NaK-ATPase and $\mathrm{Ca}-$ II than the outer pigment epithelium. Section stained for band III (c) is negative. $\times 470$. 
reactivity previously (Siegel et al. 1984; Kumpulainen 1979; Holthöfer et al. 1987) and gave specific immunoreactivity in this study, too.

Corneal transparency depends upon the dehydration of the corneal stroma by the endothelial fluid pump (Maurice 1957, 1972). The endothelial pump, which is still incompletely understood, is an energy-dependent process that can be inhibited both by specific inhibitors of NaK-ATPase (i.e. ouabain) (Trenberth \& Mishima 1968) and of carbonic anhydrase (Fischbarg \& Lim 1974). For its action, the endothelial pump needs sodium and bicarbonate ions (Dickstein \& Maurice 1972; Hodson 1979; Doughty \& Maurice 1988; Savion et al. 1989). The view that the endothelial pump is inhibited by ouabain and stimulated by sodium suggests the involvement of NaK-ATPase in this process (Riley 1982; Savion \& Farzame 1986). This view is further supported by the present findings on the presence of NaK-ATPase immunoreactivity in the corneal endothelium. Endothelial carbonic anhydrase has also been suggested to be responsible for stromal dehydration (Fischbarg \& Lim 1982; Riley 1982); in support of this we found Ca-II immunoreactivity not only in the corneal endothelium, but also in the capillary endothelium of the limbus.

There are various reasons for believing that bicarbonate ions stimulate the endothelial pump: the presence of carbonic anhydrase providing the necessary bicarbonate and protons (Fischbarg \& Lim 1974), the previously shown presence and action of bicarbonate dependent ATPase (Riley \& Peters 1981) and the existence of a bicarbonate-sensitive and ouabain-insensitive potassium-pump at this site (Savion et al. 1989). Our present data show the presence of carbonic anhydrase and NaK-ATPase in the ciliary epithelium and in the corneal endothelium, and although limited in providing direct functional data, shows the necessary enzyme reactivities at physiologically reasonable sites. ATPases are a family of enzymes expressed in various tissues including the eye (Flügel \& Lütjen-Drecoll 1988). Like in other tissues, these have distinct functions. Histochemical techniques used to study the localization of the NaK-ATPase, involved in the active exchange of intracellular sodium ion for extracellular potassium have, however, often resulted in the detection of other ATPases. This is due to the heavy metal trapping agents used for the production of the visible reaction product (Rosenthal et al. 1970; Jacobsen \& Jørgensen 1969; Ernst 1972;
Firth 1974). Thus, the previously used techniques often either failed to give precise tissue localization or did not meet the requirements of enzyme specificity. The histochemical investigations using Wachstein-Meisel (1957) - based techniques, in which ATP is used as substrate and Pb-ions as trapping agent, localized the reaction product mainly in the epithelial cell membranes (Kaye \& Tice 1966; Tervo \& Palkama 1975). However, techniques based on the hydrolysis of the artificial substrate paranitrophenyl phosphate in the presence of potassium ions (Ernst 1972) give essentially similar localization for corneal NaK-ATPase; weak reaction in the basal epithelial cell membranes and a stronger activity in the endothelium (Leuenberger \& Novikoff 1974; Tervo et al. 1977) as the present immunohistochemical technique. In the ciliary epithelium, NaK-ATPase has been reported in the lateral interdigitations of the non-pigmented epithelium (Kaye \& Pappas 1965; Shiose \& Sears 1966): the location is in concordance with our results. In respect to the ciliary epithelium, our immunohistochemical technique also gave consistent results with the earlier studies (Bhattacherjee 1971; Kumpulainen 1983).

The recently introduced immunocytochemical approach for NaK-ATPase as well as for other enzymes offers a possibility to avoid many problems of substrate specificity, enzyme inhibition or diffusion of reaction product of the histochemical techniques (Firth 1974; Kashgarian 1984). In addition, immunohistochemical techniques offer and additional advantage by allowing simultaneous detection of several different immunoractivities in the same tissue section. This may further facilitate the studies concerning the colocalization of pump sites.

Band III glycoprotein of erythrocytes is a bicarbonate-chloride exchanger molecule, crucial also in the regulation of intra- versus extracellular acidity in various tissue sites (Knauf 1979; Holthöfer et al. 1987). This suggests that band III is involved in the homeostasis of acid-base balance also in the corneal endothelium. In support to this, the present results show that both Ca-II, providing the necessary bicarbonate ions, and band III can be found in the same cytologic sites in corneal endothelium. NaK-ATPase, on the other hand, may be regulated primarily by intracellular $\left[\mathrm{Na}^{+}\right]$, by extruding intracellularly accumulating $\mathrm{Na}^{+}$-ions and water. NaK-ATPase was localized in this study also 
in corneal endothelium. It is thus a plausible hypothesis that since all three transport enzymes were found in the same cytologic site, the intracellular $\left[\mathrm{Na}^{+}\right] /\left[\mathrm{H}^{+}\right]$ratio is a common factor in the regulation of these three enzymes to maintain ionic and water homeostasis in the cornea.

\section{Acknowledgments}

The expert technical assistance of Ms Riitta Väisänen is gratefully acknowledged.

This study was supported by The Finnish Kidney Foundation, The Finnish Diabetes Foundation and the Finnish Cultural Foundation.

\section{References}

Becker B (1959): Carbonic anhydrase and the formation of aqueous humor. Am J Ophthalmol 47: 342-361.

Becker B \& Constant M A (1955): Experimental tonography: the effect of carbonic anhydrase acetazolamide on aqueous flow. Arch Ophthalmol 54: 321-329.

Bhattacherjee P (1971): Distribution of carbonic anhydrase in the rabbit eye as demonstrated histochemically, Exp Eye Res 12: 356-359.

Bonting S L \& Becker B (1964): Studies on Na-K activated adenosine triphosphatase. Invest Ophthalmol Vis Sci 3: 523-533.

Bonting S L, Simon K A \& Hawkins N M (1961): Studies on sodium-potassium activated adenosine triphosphatase. Quantitative distribution in several tissues. Arch Biochem Biophys 95: 416-423.

Cole D F (1964): Location of ouabain-sensitive adenosine triphosphatase in ciliary epithelium. Exp Eye Res 3: 72-75.

Cole D F (1977): Secretion of the aqueous humor. Exp Eye Res 25 (Suppl): 161-176.

Dickstein S \& Maurice D (1972): The metabolic basis to the fluid pump in the cornea. J Physiol (Lond) 221: 2941.

Doughty M J \& Maurice D (1988): Bicarbonate sensitivity of rabbit corneal endothelium pump in vitro. Invest Ophthalmol Vis Sci 29: 216-223.

Ernst S A (1972): Transport adenosine triphosphatase cytochemistry. Biochemical characterization of cytochemical medium for the ultrastructural localization of ouabain sensitive, potassium dependent potassium activity in the avian salt gland. J Histochem Cytochem 20: 13-22.

Firth J A (1974): Problems of specificity in the use of strontium capture technique for the cytochemical localization of ouabain-sensitive, potassium dependent phosphatase in mammalian renal tubules.J Histochem Cytochem 22: 1163-1168.
Fischbarg J \& Lim J J (1974): Role of cations, anions and carbonic anhydrase in fluid transport across rabbit corneal endothelium. J Physiol (Lond) 241: 647-675.

Flügel C \& Lütjen-Drecoll E (1988): Vorkommen und vorteilung der NaK-ATPase im ziliarkörperepithele des Kaninchens. Fortschr Ophthalmol 85: 46-49.

Guth L \& Albers R W (1974): Histochemical demonstation of $\left(\mathrm{Na}^{+} \mathrm{K}^{+}\right)$-activated adenosine triphosphatase. $\mathrm{J}$ Histochem Cytochem 22: 320-326.

Hazen-Martin D J, Pasternack G, Spicer S S \& Sens D A (1986): Immunolocalization of band 3 in normal and cystic fibrosis skin.J Histochem Cytochem 34: 823-826.

Hodson S (1979): Evidence for bicarbonate dependent sodium pump in the corneal endothelium. Exp Eye Res 11: 20-29.

Holthöfer $\mathrm{H}$ (1987): Ontogeny of cell-type specific enzyme reactivities in kidney collecting ducts. Pediatr Res 22: 504-508.

Holthöfer H, Schulte B A, Pasternack G, Siegel G J \& Spicer S S (1987): Immunocytochemical characterization of carbonic anhydrase rich cells in the rat kidney collecting duct. Lab Invest 57: 150-157.

Holthöfer H, Kumpulainen T \& Rapola J (1990): Polycystic disease of the kidney. Evaluation and classification based on nephron segment and cell-type specific markers. Lab Invest 62: 363-369.

Jacobson N O \& Jørgensen P L (1969): A quantitative biochemical and histochemical study of the lead method for localization of adenosine triphosphate hydrolyzing enzymes. J Histochem Cytochem 17: 443-452.

Kashgarian M (1984): Use of monoclonal antibodies in the study of renal function. Am J Physiol 247: F533F538.

Kaye G I \& Pappas G D (1965): Studies on the ciliary epithelium and zonule. III. The fine structure of the rabbit ciliary epithelium in relation to the localizatin of ATPase activity. J Microsc 4: 497-508.

Kaye G I \& Tice L W (1966): Studies on the cornea. Electron microscopic localization of adenosine triphosphatase activity in the rabbit cornea in relation to transport. Invest Ophthalmol Vis Sci 5: 22-31.

Knauf P A (1979): Erythrocyte anion exchange and the band 3 protein transport kinetics and molecular structure. Curr Top Membr Transp 12: 249-363.

Kumpulainen T (1979): Immunohistochemical localization of human carbonic anhydrase isoenzyme $C$. Histochemistry 62: 271-280.

Kumpulainen $T$ (1983): Immunohistochemical localization of carbonic anhydrase $\mathrm{C}$ in the epithelium of the human ciliary process. Histochemistry 77: 281-284.

Leuenberger P M \& Novikoff A B (1974): Localization of adenosine triphosphatase in rat cornea. $\mathrm{J}$ Cell Biol 60: 721-731.

Maurice D M (1957): The structure and transparency of the cornea. J Physiol (Lond) 136: 263-286. 
Maurice D M (1972): The location of the fluid pump in the cornea. J Physiol (Lond) 221: 43-54.

Riley M (1982): Transport of ions and metabolites across the corneal endothelium. In: McDevitt (ed). Cell biology of the eye. Academic Press, New York, pp 53-95.

Riley M V \& Peters M I (1981): The localization of the anion sensitive ATPase activity in the corneal endothelium. Biochim Biophys Acta 644: 251-256.

Rosenthal A S, Moses H L \& Guote C E (1970): Interpretation of phosphatase cytochemical data. J Histochem Cytochem 18: 915.

Savion N, Farzame N \& Berlin H B (1989): Characterization of bicarbonate dependent potassium uptake in cultured corneal endothelial cells. Invest Ophthalmol Vis Sci 30: 690-697.

Savion N \& Farzame N (1986): Characterization of the Na,K-ATPase pump in the cultured bovine corneal endothelial cells. Exp Eye Res 43: 355-363.

Shiose Y \& Sears M L (1966): Fine structural localization of nucleoside activity in the ciliary epithelium of albino rabbits. Invest Ophthalmol Vis Sci 5: 152-165.

Siegel G J, Holm C, Schreiber J H, Desmond T \& Ernst S A (1984): Identification of mouse brain NaK-ATPase catalytic unit. Characterization of antiserum and immunocytolchemical localization in cerebellum, choroid plexus and kidney. J Histochem Cytochem 32: 1309-1318.
Tervo T \& Palkama A (1975): Electron microscopic localization of the adenosine triphosphatase (NaK-ATPase) activity in the rat cornea. Exp Eye Res 21: 269-279.

Tervo T, Palva M \& Palkama A (1977): Transport adenosien triphosphatase activity in the rat cornea. A comparative histochemical study. Cell Tissue Res 176: 431443.

Trenberth S M \& Mishima S (1968): The effect of ouabain on the rabbit corneal endothelium. Invest Ophthalmol Vis Sci 7: 44-52.

Wachstein M \& Meisel E (1957): Histochemistry of hepatic phosphatases at a physiologic pH. Am J Clin Pathol 27: 13-23.

Received on December 27th, 1989.

Author's address:

Harry Holthöfer, MD, Ph.D,

Department of Bacteriology and Immunology,

University of Helsinki,

Haartmaninkatu 3,

SF-00290 Helsinki,

Finland,

Telefax (intl): 35804346382. 